\title{
Differences between Proximal and Distal Muscle Activity of the Lower Limbs of Community- dwelling Women during the 6-minute Walk Test
}

\author{
Hikaru Ihira, MSc, PT ${ }^{1,2)}$, Hiroyuki Shimada, PhD, MSc, PT ${ }^{3)}$, Megumi Suzukawa, PhD, \\ MSc, PT ${ }^{4)}$, Taketo Furuna, PT ${ }^{1)}$, Kiyoji Matsuyama, PhD, MD ${ }^{1)}$, Sumio Ishiai, PhD, MD ${ }^{5)}$ \\ 1) Graduate School of Health Sciences, Sapporo Medical University: South 1, West 17, Chuo-ku, \\ Sapporo 060-8556, Japan. \\ TEL: +81 11-611-2111(ext.3867),FAX:+81-11-618-5220,E-mail: ihirah@sapmed.ac.jp \\ 2) Department of Rehabilitation, Sapporo Medical University Hospital \\ 3) Section for Health Promotion, Department of Health and Medical Care, Center for Development of \\ Advanced Medicine for Dementia, National Center for Geriatrics and Gerontology \\ 4) Faculty of Health Sciences, Department of Rehabilitation, Course of Physical Therapy, University of \\ Human Arts and Sciences \\ 5) Department of Rehabilitation, Sapporo Medical University School of Medicine
}

\begin{abstract}
Purpose] This study examined the change in the muscle activities of the lower limbs during the 6-minute walk test to identify the relationship between the change in muscle activity and physical performance of community-dwelling elderly women. [Methods] Twenty-three elderly women (mean age: 77.9 years) were recruited from the community to participate. Their muscle activities were recorded using surface electromyography of the gastrocnemius, tibialis anterior, vastus medialis, hamstrings, and gluteus medius, and muscle strength, mobility, balance and 6-minute walking distance were also measured. [Results] The decrease of electromyography activity during the 6-minute walk test was significantly greater in the gastrocnemius and tibialis anterior than in the other muscles. The decrease of electromyography activity in the gastrocnemius was correlated with the timed up-and-go time $(\mathrm{r}=$ $-0.435)$ and that of the tibialis anterior was correlated with the timed up-and-go time $(\mathrm{r}=-0.530)$ and walking distance $(r=0.482)$. [Conclusions] The electromyogram activities of the gastrocnemius and the tibialis anterior showed deterioration during the 6-minute walk test, and they were correlated with gait performance. These results suggest that muscle activity of the distal muscles plays an important role in the walking ability of elderly women.

Key words: Older adult, Electromyography, Lower limb
\end{abstract}

(This article was submitted Sep. 8, 2011, and was accepted Oct. 19, 2011)

\section{INTRODUCTION}

The ability to walk a long distance is an important factor in the maintenance of independence by elderly people, because it is related to the motor function required for them to undertake activities of daily living In addition to the loss of independence, reduced walking ability and motor function have other important implications. Both factors have been reported to be associated with an increased risk of morbidity 2,3 and mortality 1,5 .

There are several tests for the objective assessment of walking ability, such as the 6-minute walk test (6MWT) and the 400-meter walk test. The 6MWT is widely used and has been shown to be a reliable and valid method for the assessment of functional exercise capacity and walking ability both of the elderly and people with chronic diseases D $^{\text {. In }}$ particular, the 6MWT can be used to assess frail and disabled patients who cannot complete submaximal endurance tests using standard cycle ergometry or a treadmill 6-minute walk distance (6MWD) is reduced in patients with obstructive lung disease, heart failure, arthritis, or neuro- muscular disease 8,9 , and these previous studies also showed that the 6MWD is correlated with endurance performance in such patients. Moreover, the 6MWT is useful as an evaluation tool not only for patients but also for community-dwelling elderly people because the extent of living space is related to favorable living functions 10 . Paul et al. 11 reported that the $6 \mathrm{MWT}$ is a useful measure related to various physical performances of community-dwelling elderly people. Other studies have also reported that endurance, evaluated by peak oxygen uptake, is associated with muscle strength 12 and functional mobility performance ${ }^{13}$. However, little is known about the relationship between muscle activity during the $6 \mathrm{MWT}$ and the physical performance of elderly people.

The purpose of this study was to evaluate the change in muscle activity of the lower limbs during the 6MWT and to determine the relationship between the change in muscle activity and the physical performance of the elderly. We hypothesized that the elderly would show a gradual decrease in muscle activity of the lower limbs as the walking distance increases. 


\section{SUBJECTS AND METHODS}

\section{Subjects}

Twenty-three elderly women (age, $77.9 \pm 2.2$ years) were recruited from the community for this study. The procedures used in this study were approved by the ethics committee of the Tokyo Metropolitan Institute of Gerontology and conformed to the principles of the Declaration of Helsinki.

\section{Methods}

The $6 \mathrm{MWT}^{14}$ measures the distance, in meters, walked at a preferred pace over a 6-minute period along a measured walkway. The $6 \mathrm{MWT}$ was conducted according to a standardized protocol, using an internal hallway, with 20-meter distances marked by colored tape on the floor. Participants were told that "the purpose of this test is to see how far you can walk in 6 minutes". They were instructed; to "Walk from end to end of the hallway at your own pace, to cover as much ground as possible." Subjects were notified that no further encouragement would be provided to them during the test. Muscle activity during the 6MWT was simultaneously recorded using surface electromyography (EMG) (Nihonkoden, Japan) from 5 muscles of the right leg: vastus medialis (VM), hamstrings (HM), gluteus medius (GM), lateral head of the gastrocnemius (GS), and tibialis anterior (TA). The EMG signals were sampled at $1000 \mathrm{~Hz}$, to quantify the EMG amplitude, and were expressed as the root mean square (RMS). The EMG data from the muscles were processed using Power Lab (AD Instruments, USA). Before any analysis was performed, all raw data were bandpass-filtered $(5-500 \mathrm{~Hz})$. EMG activity was simultaneously monitored during the $6 \mathrm{MWT}$. All the recordings were digitized and stored on a PC for offline analyses at a later time. A gait cycle was defined as the temporal interval between the beginning of the initial heel contact and the beginning of the next heel contact (Fig. 1). The RMS of each muscle was calculated immediately at the start of walking and over a gait cycle after 1, 3, and 6 minutes. The RMS and time of gait cycle (t-GC) were averaged for 3 consecutive gait cycles to represent muscle activity and $\mathrm{t}-\mathrm{GC}$. We chose the EMG parameters of a previous study by Murley et al. ${ }^{15}$ that demonstrated the sensitivity to change in the biomechanics of motion during gait. In addition, we calculated the ratio of the RMS and t-GC after 1, 3, and 6 minutes to their respective values immediately after the start of the $6 \mathrm{MWT}$.

For the evaluation of the muscle strengths of ankle dorsiflexion and plantar flexion, we measured the isometric muscle force using a hand-held dynamometer ( $\mu$-tus F1, Anima Co., Tokyo, Japan). We also measured the timed up-and-go (TUG) and one-legged standing (OLS) time as evaluations of physical performance because it has been reported that they are related to $6 \mathrm{MWD}$. The maximal strength of the ankle muscles responsible for ankle dorsiflexion and plantar flexion were assessed using a dynamometer fixed to a footstool ${ }^{16}$. The TUG was performed according to the standard method that measures the time taken to rise from a chair, walk 3 meters, turn, and return to a sitting position ${ }^{17}$. OLS was performed for up to 60 seconds twice on each leg. Subjects stood with their lifted foot approximately 2 inches from

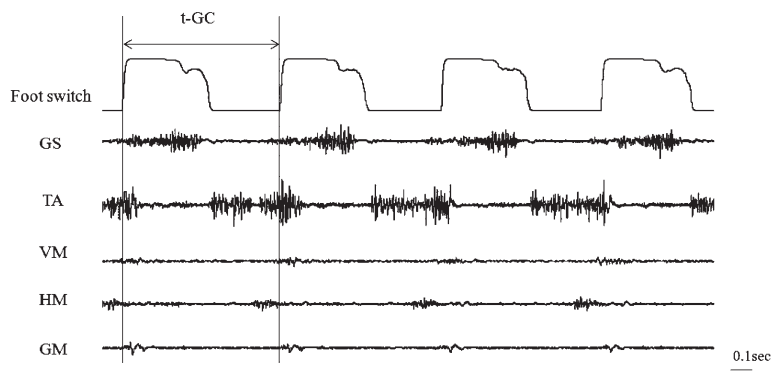

Fig. 1. Representative EMG recordings collected during the 6-min walk test performed by elderly women. Raw data of the gastrocnemius (GS), tibialis anterior (TA), vastus medialis (VM), hamstrings (HM) and gluteus medialis (GM). The solid line indicates the onset of heel contact, and t-GC presents the time of the gait cycle.

the medial malleolus of the stance foot without making footto-malleolus contact. For the OLS, subjects stood first on their preferred leg, then on their preferred leg again, while keeping both arms hanging down naturally 18 .

One-way analysis of variance (ANOVA) was performed to analyze the changes of the EMG activity among the 3 timed intervals $(1,3$, and 6 minutes from the start). Post hoc analyses were performed using adjusted Bonferroni tests. Spearman correlation coefficients were used to assess relationships between GS and TA after 6 minutes and each of the physical performance parameters. The multiple-regression analysis stepwise method was used to determine the relative contributions of the muscles to t-GC. In a t-GC model adjusted for age and height, selected independent variables were determined by the ratios of VM, HM, GM, GS, and TA muscles at 1 versus 6 minutes from the start. SPSS version 15.0 was used to analyze the data, and values of $p<0.05$ were considered significant.

\section{RESULTS}

Table 1 displays the characteristics of the subjects. The ANOVA results indicate statistically significant differences in EMG amplitudes of GS $\left(\mathrm{F}_{2,44}=6.4, \mathrm{p}<0.05\right)$ and TA $\left(\mathrm{F}_{2}\right.$, $\left.{ }_{44}=5.3, p<0.05\right)$. There were no significant differences in the EMG amplitudes of $\mathrm{VM}\left(\mathrm{F}_{2,44}=0.9, \mathrm{p}=0.40\right), \mathrm{HM}\left(\mathrm{F}_{2}\right.$ $\left.{ }_{44}=1.6, p=0.2\right)$ and $\mathrm{GM}\left(\mathrm{F}_{2,44}=0.9, \mathrm{p}=0.41\right)$ (Table 2). Multiple stepwise regression analysis revealed that $\mathrm{t}-\mathrm{GC}$ after 1 minute from the start of walking could not be explained by any of the muscles at that time. In contrast, the t-GC 6 minutes from the start of walking could be best explained by the ratio of TA muscle activity; this variable explained $21 \%$ of the variation in $\mathrm{t}-\mathrm{GC}$.

Table 3 shows the Pearson's correlation coefficients between the ratios of muscle activities of GS and TA after 6 minutes and TUG, and walking distance measures. The ratio of muscle activity of GS after 6 minutes was highly correlated with TUG $(\mathrm{r}=-0.435, \mathrm{p}<0.05)$, and that of TA after 6 minutes was highly correlated with TUG and walk- 
Table 1. Characteristics of the subjects

\begin{tabular}{lrr}
\hline & Mean & S.D. \\
\hline Age (year) & 77.9 & 2.2 \\
Height (cm) & 147.6 & 3.8 \\
Weight (kg) & 49.3 & 4.3 \\
PF strength (N) & 324.7 & 101.9 \\
DF strength (N) & 174 & 19.6 \\
TUG (sec) & 6.01 & 0.6 \\
OLS (sec) & 39.4 & 21.1 \\
Distance (m) & 396.3 & 46.6 \\
\hline
\end{tabular}

Data are expressed as means $\pm \mathrm{SD}$.

$\mathrm{PF}=$ plantar flexion, $\mathrm{DF}=$ dorsal flexion, $\mathrm{TUG}=$ timed up-and-go test, OLS= onelegged standing

ing distance $(\mathrm{r}=-0.530, \mathrm{r}=0.482, \mathrm{p}<0.05)$. No correlations were observed between GS and TA after 6 minutes and age $(\mathrm{r}=0.249, \mathrm{r}=0.112)$, height $(\mathrm{r}=0.106, \mathrm{r}=0.134)$, weight $(\mathrm{r}=$ $-0.073, \mathrm{r}=-0.166)$, plantar flexion strength $(\mathrm{r}=0.097, \mathrm{r}=$ $-0.045)$, dorsal flexion strength $(\mathrm{r}=-0.118, \mathrm{r}=-0.154)$, or OLS $(r=0.269, r=-0.269)$.

\section{DISCUSSION}

We measured EMG of the VM, HM, GM, TA, and GS muscles to evaluate the proximal and distal muscle activities of the lower limbs of community-dwelling elderly women during the 6MWT. In addition, we also measured muscle strength, mobility, balance, and walking distance to examine the relationship between their changes in muscle activity during the 6MWT and physical performance.

The main finding of this study was that the EMG activi- ties of the GS and TA (distal muscles) were significantly decreased during the 6MWT, whereas there were no significant changes in VM, HM, and GM (proximal muscles) of the elderly women. We believe that the declines observed in EMG amplitudes, representing declines in muscle activation, are indicative of a decrease in motor unit firing and/or a recruitment of motor units in the course of 6MWT. These neural structures may deteriorate with age, and therefore, may not be able to maintain the activity of the distal muscles of the elderly during the 6MWT. A previous study ${ }^{199}$ suggested that age-related changes in the skeletal muscle properties, such as muscle fiber types, are factors contributing to falls by the elderly. Additionally, many studies ${ }^{2-25}$ have proposed that the mechanism associated with decreased muscle activation is the change in the proportion of muscle fiber types. For example, the balance of shared versus unshared inputs to motor units can be altered by age-related changes in spindles, including increased capsular thickness, a decrease in the number of intrafusal fibers per spindle, spherical axonal swelling, and degenerative changes in the spindle neuromuscular end plates due to atrophy ${ }^{20}$. These changes modify afferent input from Golgi tendon organs that are sensitive to contractions of single motor units 27 . Therefore, with increasing age, human skeletal muscles gradually decrease in volume, as the number of motor units and muscle fibers, and the size of type 2 fibers are reduced. As a result, progressive weakening and impaired mobility may occur, especially in endurance activities. In general, decrease of muscle volume has attributed to muscle atrophy of the proximal muscles such as quadriceps muscle 28, 29, but the relationship with neural activation and muscle strength has not been elucidated. For example, in the lower limbs, substantial age-related weakness in the proximal muscles, such as the quadriceps muscle, does not appear to be related to changes in neural drive 9 . Other studies have also shown no significant limitation of activation ability in the quadriceps of subjects approximately 80 years of

Table 2. Ratios of EMG activities in the four time periods

\begin{tabular}{ccccc}
\hline & immediately after & 1 minute & 3 minutes & 6 minutes \\
\hline GS* $^{*}$ & 100 & $103.1 \pm 26.9$ & $95.2 \pm 21.1$ & $91.6 \pm 26.2$ \\
TA* $^{*}$ & 100 & $99.3 \pm 11.8$ & $96.4 \pm 14.4$ & $89.3 \pm 15.7$ \\
$\mathrm{VM}$ & 100 & $104.6 \pm 19.2$ & $102.3 \pm 26.6$ & $97.6 \pm 24.2$ \\
$\mathrm{HM}$ & 100 & $96.4 \pm 21.9$ & $91.1 \pm 14.8$ & $88.6 \pm 15.6$ \\
$\mathrm{GM}$ & 100 & $101.8 \pm 14.8$ & $101.2 \pm 13.3$ & $98.3 \pm 14.1$ \\
\hline
\end{tabular}

Table 3. Correlation between the ratio of muscle activity and TUG and walking distance

\begin{tabular}{lcc}
\hline Variable & Muscle & Correlation coefficient (r) \\
\hline TUG & GS after 6-min & $-0.435^{*}$ \\
& TA after 6-min & $-0.530^{*}$ \\
Walking distance & GS after 6-min & 0.358 \\
& TA after 6-min & $0.482^{*}$ \\
\hline
\end{tabular}

Date are expressed as means \pm SD. $*$ p $<0.05$. GS after 6 -min: gastrocnemius muscle after 6 minutes, TA after 6 -min: tibialis anterior muscle after 6 minutes, $\mathrm{TUG}=$ timed up-and-go test 
age 1,32 . In contrast, it has been reported that the TA muscle shows a reduced number of motor unit 3 , and the ability to generate power is markedly impaired during maximal isotonic strength performed by the elderly 3 .

From the viewpoint of kinematics, muscle activity at the ankle performs two functions related to resistance to gravity during ambulation: control of the foot position at heel contact for both swing (TA), and forward propulsion (GS). At slower walking speeds, the TA biphasic EMG pattern is intact because of the need to control the foot against gravity. Furthermore, the GS muscle maintains the same phasic pattern, indicating the continuing need for forward progression even at the slower walking speeds of the elderly ${ }^{\beta}$. The significant associations between lower limb strength, velocity, and step length found in our study are consistent with the results of previous studies 36,37 , and indicate that the normal age-related decline in leg strength may be the primary limiting factor that prevents older people from walking at speeds equivalent to younger people. Bassey et al. $\$$ found that elderly community-dwelling men and women with reduced ankle dorsiflexor strength have slow self-selected walking speeds. Our study also showed that EMG activities of the distal muscles of community-dwelling elderly women significantly decrease during the 6MWT. This was confirmed by multiple stepwise regression which identified TA muscle activity after 6 minutes as the independent contributor to $\mathrm{t}-\mathrm{GC}$, explaining approximately $21 \%$ of the variance. We consider that the distal muscles (e.g., TA muscle) fatigue more easily than the proximal muscles in the elderly during walking. Many studies have demonstrated a direct relationship between muscle strength and EMG activity ${ }^{39-41}$. In the present study, we found no correlation between GS and TA muscle force and the ratio of EMG activity 6 minutes after the start of walking. In contrast, significant relationships were found between TUG tine, walking distance, and the ratios of the EMG activities of the distal muscles. This suggests that the change in the ratios of distal muscle activities during the 6MWT might be useful for the evaluation of the physical performance of community-dwelling elderly women.

The subjects of the present study were limited to healthy elderly women; therefore, our findings may not translate directly to understanding frail elderly women. However, we found differences in muscle activation dynamics even in healthy elderly women who did not exhibit poor muscle strength, mobility, and balance that might otherwise indicate functional decline 4 . Therefore, the observed changes in muscle activation dynamics may be a precursor to future functional declines. Early detection of these changes may help prevent further loss of gait function. This requires further investigation in a clinical outcomes study.

\section{ACKNOWLEDGEMENTS}

This study was supported by a Grant-in-Aid for Scientific Research from the Ministry of Education and Culture of Japan.

\section{REFERENCES}

1) Guralnik JM, Branch LG, Cummings SR, et al.: Physical performance measures in aging research. J Gerontol, 1989, 44: M141-M146. Medline

2) Lakka TA, Ven ä 1 ä inen JM, Rauramaa R, et al.: Relation of leisure-time physical activity and cardiorespiratory fitness to the risk of acute myocardial infarction in men. N Engl J Med, 1994, 330: 1549-1554. MedlineCrossRef

3) Newman AB, Simonsick EM, Naydeck BL, et al.: Association of long-distance corridor walk performance with mortality, cardiovascular disease mobility limitation, and disability. JAMA, 2006, 295: 2018-2026. Medline CrossRef

4) Blair SN, Kohl HW 3rd, Paff enbarger RS Jr, et al.: Physical fitness and allcause mortality. A prospective study of healthy men and women. JAMA, 1989, 262: 2395-2401. [Medline] [CrossRef]

5) Myers J, Prakash M, Froelicher V, et al.: Exercise capacity and mortality among men referred for exercise testing. N Engl J Med, 2002, 346: 793-801. Medline CrossRef

6) Solway S, Brooks D, Lacasse Y, et al.: A qualitative systematic overview of the measurement properties of functional walk tests used in the cardiorespiratory domain. Chest, 2001, 119: 256-270. Medline [CrossRef

7) Peeters P, Mets T: The 6 minute walk as an appropriate exercise test in elderly patients with chronic heart failure. J Gerontol A Biol Sci Med Sci, 1996, 51: M147-M151. Medline

8) McGavin CR, Artvinli M, Naoe H, et al.: Dyspnea, disability, and distance walked: comparison of estimates of exercise performance in respiratory disease. BMJ, 1978, 2: 241-243. [Medline] CrossRef]

9) Bittner V, Weiner DH, Yusuf S, et al.: Prediction of mortality and morbidity with a six minute walk test in patients with left ventricular dysfunction. JAMA, 1993, 270: 1702-1707. [Medline [CrossRef

10) Shimada H, Sawyer P, Harada K, et al.: Predictive validity of the classification schema for functional mobility tests in instrumental activities of daily living decline among older adults. Arch Phys Med Rehabil, 2010, 91: 241-246. [Medline [CrossRef

11) Enright PL, McBurnie MA, Bittner V, et al.: Cardiovascular Health Study: The 6-min walk test a quick measure of functional status in elderly adults. Chest, 2003, 123: 387-398. Medline] [CrossRef]

12) Segerström AB, Holmbäck AM, Hansson O, et al.: Relation between cycling exercise capacity, fiber-type composition, and lower extremity muscle strength and muscle endurance. J Strength Cond Res, 2011, 25: 16-22. [Medline [CrossRef

13) Alexander NB, Dengel DR, Olson RJ, et al.: Oxygen-uptake (VO2) kinetics and functional mobility performance in impaired older adults. J Gerontol A Biol Sci Med Sci, 2003, 58: M734-M739. Medline [CrossRef

14) Butland RJ, Pang J, Gross ER, et al.: Two-, six-, and 12-minute walking tests in espiratory disease. BMJ, 1982, 284: 1607-1608. Medline [CrossRef

15) Murley GS, Menz HB, Landorf KB: Foot posture influences the electromyographic activity of selected lower limb muscles during gait. J Foot Ankle Res, 2009, 2: 35. Medline [CrossRef

16) Wang CY, Olson SL, Protas EJ: Test-retest strength reliability: hand-held dynamometry in community-dwelling elderly fallers. Arch Phys Med Rehabil, 2002, 83: 811-815. [Medline CrossRef

17) Podsiadlo D, Richardson S: The timed 'Up \& Go': A test of basic functional mobility for frail elderly persons. J Am Geriatr Soc, 1991, 39: 142-148. Medline

18) Vellas BJ, Wayne SJ, Romero L, et al.: One-leg balance is an important predictor of injurious falls in older persons. J Am Geriatr Soc, 1997, 45: 735-738. [Medline]

19) Jubrias SA, Odderson IR, Esselman PC, et al.: Decline in isokinetic force with age: muscle cross-sectional are and specific force. Pflugers Arch, 1997, 434: 246-253. [Medline] [CrossRef]

20) Erim Z, Beg MF, Burke DT, et al.: Effects of aging on motor-unit contro properties. J Neurophysiol, 1999, 82: 2081-2091. Medline

21) Lexell J: Human aging, muscle mass, and fiber type composition. J Gerontol A Biol Sci Med Sci, 1995, 50: 11-16. [Medline]

22) Henneman E, Somjen G, Carpenter DO: Functional significance of cell size in spinal motorneurons. J Neurophysiol, 1965, 28: 560-580. Medline

23) Milner-Brown HS, Stein RB, Temm R: The contractile properties of human motor units during voluntary isometric contraction. J Physiol, 1973, 228: 285-306. Medline

24) Nelson RM, Soderberg GL, Urbscheit NL: Alterations of motor-unit discharge characteristics in aged human. Phys Ther, 1984, 64: 29-34. [Medline

25) Soderberg GL, Minor SD, Nelson R: A comparison of motor unit behavior in young and aged subjects. Age Ageing, 1991, 20: 8-15. [Medline] [Cross- 
Ref

26) Swash M, Fox KP: The effect of age on human skeletal muscle: studies of the morphology and innervation of muscle spindles. J Neurol Sci, 1972, 16: 417-432. [Medline CrossRef

27) Binder MD, Kroin JS, Moore GP, et al.: The response of Golgi tendon organs to single motor unit contractions. J Physiol, 1977, 271: 337-349. Medline

28) Adams GR, Hather BM, Dudley GA: Effect of short-term unweighting on human skeletal muscle strength and size. Aviat Space Environ Med, 1994 65: 1116-1121. Medline

29) Berg HE, Dudley GA, Haggmark T, et al: Effects of lower limb unloading on skeletal muscle mass and function in humans. J Appl Physiol, 1991, 70 1882-1885. [Medline

30) Roos MR, Rice CL, Connelly DM, et al.: Quadriceps muscle strength, contractile properties, and motor unit firing rates in young and old men. Muscle Nerve, 1999, 22: 1094-1103. [Medline [CrossRef]

31) Harridge SD, Kryger A, Stensgaard A: Knee extensor strength, activation, and size in very elderly people following strength training. Muscle Nerve, 1999, 22: 831-839.

32) Hurley MV, Rees J, Newham DJ: Quadriceps function, proprioceptive acuity and functional performance in healthy young, middle-aged and elderly subjects. Age Ageing, 1998, 27: 55-62. [Medline [CrossRef]

33) McNeil CJ, Doherty TJ, Stashuk DW, et al.: Motor unit number estimates in the tibialis anterior muscle of young, old, and very old men. Muscle Nerve, 2005, 31: 461-467. [Medline CrossRef

34) McNeil CJ, Vandervoort AA, Rice CL: Peripheral impairments cause a progressive age-related loss of strength and velocity-dependent power in the dorsiflexors. J Appl Physiol, 2007, 102: 1962-1968. [Medline CrossRef

35) Nymark JR, Balmer SJ, Melis EH, et al.: Electromyographic and kinematic nondisabled gait differences at extremely slow overground and treadmill walking speeds. J Rehabil Res Dev, 2005, 42: 523-534. [Medline] [CrossRef

36) Lord SR, Lloyd DG, Li SK: Sensori-motor function, gait patterns and falls in community-dwelling women. Age Ageing, 1996, 25: 292-299. Med[ine] CrossRef

37) Buchner DM, Larson EB, Wagner EH, et al.: Evidence for a non-linear relationship between leg strength and gait speed. Age Ageing, 1996, 25: 386-391. [Medline CrossRef

38) Bassey EJ, Bendall MJ, Pearson M: Muscle strength in the triceps surae and objectively measured customary walking activity in men and women over 65 years of age. Clin Sci, 1988, 74: 85-89. [Medline

39) Karlsson S, Gerdle B: Mean frequency and signal amplitude of the surface EMG of the quadriceps muscles increase with increasing torque-a study using the continuous wavelet transform. J Electromyogr Kinesiol, 2001, 11: 131-140. [Medline] CrossRef

40) De Luca CJ: The use of surface electromyography in biomechanics. J Appl Biomech, 1997, 13: 1-38.

41) Linnamo V, Moritani T, Nicol C, et al.: Motor unit activation patterns during isometric, concentric and eccentric actions at different force levels. J Electromyogr Kinesiol, 2003, 13: 93-101. [Medline] [CrossRef]

42) Alexander NB: Gait Disorders in Older Adults. J Am Geriatr Soc, 1996, 44: 434-451. [Medline 